\title{
ISOTHERM STUDIES OF MALACHITE GREEN REMOVAL BY YARN PROCESSING SLUDGE-BASED ACTIVATED CARBON
}

\author{
BADANIE IZOTERM USUWANIA ZIELENI MALACHITOWEJ \\ PRZEZ OSAD ŚCIEKOWY MODYFIKOWANY WĘGLEM AKTYWNYM
}

\begin{abstract}
Adsorption is an effective wastewater treatment technique which has been widely used in various industrial applications. However, the high operation cost involving commercial activated carbon in industrial processes is the main drawback. Sewage sludge is an auspicious precursor of activated carbon owing to its high carbon content, rich functional groups, low cost, high availability and abundance. This research was aimed to establish the feasibility of converting yarn processing sludge into activated carbon by $\mathrm{KI}+\mathrm{KOH}$ activation and char at $700{ }^{\circ} \mathrm{C}$ for $1 \mathrm{~h}$. The effect of preparation strategies on the properties of sludge-based adsorbents (SBA) was reviewed. The applications of SBAs in the removal of dyes and model pollutants were discussed. The results from this study proved that the preparation of yarn processing sludge-based activated carbon via $\mathrm{KI}+\mathrm{KOH}$ activation is feasible and effective in the adsorption of dye. This paper provides further insight on the preparation methods of sludge-based adsorbents and dye wastewater treatment using these adsorbents.
\end{abstract}

Keywords: adsorbent, adsorption, chemical activation, dye removal, sludge

\section{Introduction}

Over the years, water pollution control has been a subject of great interest. In most developing countries, the wide commercialization of yarn, fabrics and textiles due to high demand has led to establishment of more factories. Yarn processing and textile manufacturing are among the largest sectors producing hazardous chemical wastewater; responsible for nearly $22 \%$ of the overall volume of industrial effluent generated [1]. However, the inadequate treatment of dye-containing effluent often results in dyes finding their ways into water streams. Dyes in water impede the penetration of sunlight for photosynthesis process, thereby reducing soluble oxygen for respiration. They are also stable to light, heat and oxidizing agents and biologically non-degradable. In addition, dyes can induce microtoxicity to aquatic creatures therein. Therefore, the removal of dyes from effluent is essential before it enters the water bodies.

\footnotetext{
${ }^{1}$ Centre of Lipids Engineering \& Applied Research, Ibnu-Sina Institute for Scientific \& Industrial Research, Universiti Teknologi Malaysia, 81310 UTM Johor Bahru, Johor, Malaysia

${ }^{2}$ School of Chemical \& Energy Engineering, Faculty of Engineering, Universiti Teknologi Malaysia, 81310 UTM Johor Bahru, Johor, Malaysia

*Corresponding author email: abbas@cheme.utm.my
} 
Adsorption is a preferable dye removal technique because the process is cheap, simple and easy to operate, requires less maintenance and space, robust and can produce high removal efficiency depending on the types of adsorbent [2, 3]. Due to expensive commercial activated carbon, i.e., the commonly used adsorbent in wastewater treatment industry, attempt has been made in this work to explore yarn processing sludge as a sustainable and promising candidate of activated carbon. The production of sewage sludge, alongside with its handling and disposal has become a subject of environmental concern in many countries worldwide. These bring about the motivation to carry out this research work. Sewage sludge is normally disposed via incineration and landfilling, but neither of these are inexpensive, environmentally friendly and sustainable methods. Hence, the use of yarn sludge as a precursor of activated carbon is a smart strategy to minimize the associated pollution in the environment.

In practice, the preparation of $\mathrm{AC}$ can be carried out either through chemical activation or physical activation. Chemical activation prevails over physical activation because the process can be performed at short activation time and low activation temperature, and can offer better yield, and higher pore volume and surface area of AC. Thus, this work was aimed at evaluating the $\mathrm{AC}$ produced from yarn processing sludge by $\mathrm{KI}+\mathrm{KOH}$ activation ratio of $1.5: 0.5: 1(\mathrm{KI}: \mathrm{KOH}: \mathrm{TS})$ at $700{ }^{\circ} \mathrm{C}$ for $1 \mathrm{~h}$. The present work reports the isotherm studies of malachite green removal by the derived activated carbon and the possible interaction mechanisms governing the adsorption.

\section{Materials and methods}

\section{Materials}

Yarn processing sludge was obtained from American \& Efird (Johor, Malaysia). Hydrochloric acid $(\mathrm{HCl}, 30 \%)$, potassium hydroxide $(\mathrm{KOH})$ pellets and malachite green (MG, CI 42000) were purchased from R\&M Marketing, UK. Potassium iodide (KI) was obtained from QREC (ASIA), Malaysia. Sodium hydroxide ( $\mathrm{NaOH}, 96 \%$ ) was supplied by Bendosen, Malaysia. All chemicals are of analytical reagent grade and were used as received without further purification.

\section{Preparation of yarn processing sludge-based activated carbon (TSAC) and char}

About $75 \mathrm{~g}$ of granular sludge (TS) was dried at $110{ }^{\circ} \mathrm{C}$ for $24 \mathrm{~h}$, crushed and sieved to a desired particle size of $0.36 \mathrm{~mm}$ using a mechanical sieve. A composite of $\mathrm{KOH}+\mathrm{KI}$ was selected as the activating agent. The chemical activation of dried sludge was performed at impregnation ratio of $1.5: 0.5: 1$ (KI : KOH : TS), activation temperature of $700{ }^{\circ} \mathrm{C}$ for $1 \mathrm{~h}$. First, the impregnation was carried out at $90{ }^{\circ} \mathrm{C}$ for $1.5 \mathrm{~h}$, and the mixture was oven-dried overnight. Subsequently, the impregnated sample was pyrolyzed in a muffle furnace, and later cooled to room temperature before it was washed sequentially with $\mathrm{HCl}$ solution and distilled water. Finally, the TSAC was dried at $110{ }^{\circ} \mathrm{C}$ overnight and kept in a desiccator. Similarly, char was prepared at $700{ }^{\circ} \mathrm{C}$ and $1 \mathrm{~h}$ without any activating agent. The yields of the resultant TSAC and char were calculated as $\left(\mathrm{m} / \mathrm{m}_{o}\right) \cdot 100$, where $m[\mathrm{~g}]$ is the mass of the activated carbon and $m_{o}[\mathrm{~g}]$ is the mass of the raw sludge.

\section{Batch adsorption}

Malachite green (MG) dye was dissolved in deionized water to prepare stock solution of $1000 \mathrm{mg} / \mathrm{dm}^{3}$. The dye stock solution was diluted to prepare solution with different dye 
concentrations. The batch adsorption experiment was carried out by adding $0.05 \mathrm{~g}$ of TSAC into $0.05 \mathrm{dm}^{3}$ of dye solution with desired concentration. The solid-solution mixtures were kept in an orbital shaker (SASTEC ST-WSZ100A) and agitated at $120 \mathrm{rpm}$ and room temperature for $72 \mathrm{~h}$. The $\mathrm{pH}$ of the solution is around 2.1. The concentration of MG was measured using a visible spectrophotometer (Drawell DU-8200) at $\lambda_{\max }=640 \mathrm{~nm}$. The dye solution in the absence of TSAC was prepared as a control for reference purpose. The adsorption capacity was calculated as, $q_{e}=\left(C_{o}-C_{e}\right) V / W$, where $C_{o}$ and $C_{e}\left[\mathrm{mg} / \mathrm{dm}^{3}\right]$ are the initial concentration and equilibrium concentration of dye solution respectively, $V\left[\mathrm{dm}^{3}\right]$ is the volume of dye solution and $W[\mathrm{~g}]$ is the mass of activated carbon which is $0.05 \mathrm{~g}$.

\section{Results and discussion}

\section{Characteristics of sludge-based activated carbon}

In this work, yarn processing sludge is a scheduled solid waste from a biological wastewater treatment process in a textile industry. The sludge is mainly made up of fiber, slurry, dyeing aid, dyestuff, akali or acid and inorganic compounds [4]. It has a high carbon content of $42.3 \%, 5.5 \%$ hydrogen, $45.7 \%$ oxygen, $5.1 \%$ nitrogen and $1.43 \%$ sulphur. However, its ash content is also high (16\%), indicating the presence of inorganic matter like calcium carbonate, kaolin and dolomite.

Although $\mathrm{KOH}$ activation is widely applied in the preparation of $\mathrm{AC}$, certain limitations still exist including low product yield, highly microporous AC (less effective for macro-pollutants removal) and toxicity of $\mathrm{KOH}$ [5]. The novel $\mathrm{KI}+\mathrm{KOH}$ activating agent produces microporous sludge-based activated carbon (TSAC) with a superior surface area of $984 \mathrm{~m}^{2} / \mathrm{g}$ and $64 \%$ microporosity as shown in Table 1 . In contrast to $\mathrm{KOH}, \mathrm{KI}+\mathrm{KOH}$ enhances the yield and textural properties of TSAC, indicating the integrated effect of KI and $\mathrm{KOH}$ [3]. KI is a mild salt with fire retardant property, whereas $\mathrm{KOH}$ is a strong base which stimulates gasification. By combining $\mathrm{KI}$ and $\mathrm{KOH}$, the stable iodide from $\mathrm{KI}$ binds to the thin pore walls and strengthens them, while the metallic potassium intercalates into the carbon matrices for further pore drilling and pore formation process. In other words, $\mathrm{KI}+\mathrm{KOH}$ composite promotes strong carbon network structure. Moreover, $\mathrm{KI}$ and $\mathrm{KOH}$ are also dehydrating agents which hinder tar formation and production of volatile substance during pyrolysis, therefore reducing the extent of sample burnt-off and enhance the final product yield. As a result, the yield and textural properties of TSAC are improved as compared to that of char (Table 1). Without the presence of $\mathrm{KI}$ and $\mathrm{KOH}$, the collapse of fragile pore walls and high ash content in sludge may hinder the development of micropores and mesopores, resulting in lower surface area. The physicochemical properties of TSAC-based activated carbons have been described elsewhere $[3,6]$.

Yield and textural properties of char and TSAC

\begin{tabular}{|l|c|c|}
\hline Sample & Char & TSAC \\
\hline Yield [\%] & 15 & 22.4 \\
\hline BET surface area $\left[\mathrm{m}^{2} / \mathrm{g}\right]$ & 11.9 & 984 \\
\hline Average pore diameter $[\mathrm{nm}]$ & - & 2.44 \\
\hline Pore volume $\left[\mathrm{cm}^{3} / \mathrm{g}\right]$ & - & 0.554 \\
\hline Micropore volume $\left[\mathrm{cm}^{3} / \mathrm{g}\right]$ & - & 0.352 \\
\hline Microporosity $[\%]$ & - & 63.6 \\
\hline
\end{tabular}




\section{Effect of initial dye concentration}

Figure 1 shows the relationship between the equilibrium adsorption $\left(q_{e}\right)$ of MG onto TSAC and the equilibrium concentration $\left(C_{e}\right)$. The adsorption capacity at equilibrium escalates with increasing concentration until a saturation point of $156 \mathrm{mg} / \mathrm{g}$ was achieved, indicating the maximum adsorption capacity. At low concentrations, $q_{e}$ is dependent on the amount of MG molecules as it is a limiting factor. In other words, the number of active sites for adsorption is more than the quantity of MG molecules. Adsorption occurs rapidly due to the high affinity between TSAC and dye molecules. As the MG concentration increases, $q_{e}$ also increases up to a certain point where it slowly stabilizes at $156 \mathrm{mg} / \mathrm{g}$ (saturation point). The greater adsorption capacity at high concentration is attributed to the increasing driving force of MG mass transfer from the bulk solution onto the TSAC surface. Generally, the number of accessible adsorption sites becomes the limiting factor at high concentration, whereas the amount of adsorbate available is the restricting factor at low concentration.

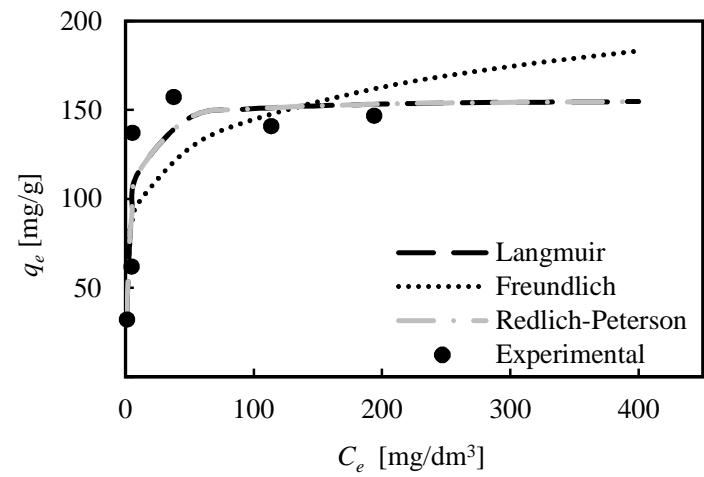

Fig. 1. Adsorption isotherm of MG on TSAC (experimental conditions: $C_{o}=30-500 \mathrm{mg} / \mathrm{dm}^{3}$, contact time $=72 \mathrm{~h}, t=25^{\circ} \mathrm{C}$, agitation speed $\left.=120 \mathrm{rpm}\right)$

\section{Equilibrium isotherm}

Generally, an adsorption isotherm is a pivotal curve illustrating the occurrence governing the mass transfer of an adsorbate from the bulk liquid phase to a solid-phase at a constant $\mathrm{pH}$ and temperature [7]. In this work, Langmuir, Freundlich and Redlich-Peterson (R-P) models were used to describe the adsorption data, and they are represented by the following equations, respectively:

$$
\begin{gathered}
q_{e}=\frac{q_{m} b C_{e}}{1+b C_{e}} \\
q_{e}=k_{F}\left(C_{e}\right)^{\frac{1}{n}} \\
q_{e}=\frac{k_{R} C_{e}}{\left(1+a_{R} \cdot C_{e}^{g}\right)}
\end{gathered}
$$

where $q_{e}[\mathrm{mg} / \mathrm{g}]$ is the adsorption capacity at equilibrium, $b\left[\mathrm{dm}^{3} / \mathrm{mg}\right]$ is the Langmuir constant, $C_{e}\left[\mathrm{mg} / \mathrm{dm}^{3}\right]$ is the residue concentration at equilibrium, $q_{m}[\mathrm{mg} / \mathrm{g}]$ is the maximum monolayer adsorption capacity, $k_{F}\left[(\mathrm{mg} / \mathrm{g})\left(\mathrm{dm}^{3} / \mathrm{mg}\right)^{1 / n}\right]$ is the Freundlich 
isotherm constant related to the adsorption capacity, $n$ is the empirical parameter related to adsorption intensity that changes with the heterogeneity of TSAC, $k_{R}\left[\mathrm{dm}^{3} / \mathrm{g}\right]$ and $a_{R}\left[\left(\mathrm{dm}^{3} / \mathrm{mg}\right) \mathrm{g}\right]$ are the R-P constants.

The curve fitting is shown in Figure 1, while the values of the isotherm parameters are tabulated in Table 2. $R^{2}$ is the determination coefficient, whereas RMSE refers to root mean square error. The Freundlich isotherm displays a poor fit, suggesting that multilayer adsorption may not predominate. The value of Freundlich constant, $n$ is 5.52, corresponds to $1 / n$ of 0.18 that is in the range of 0 to 1 , signifying a favourable ideal Langmuir adsorption and chemisorption [2,7]. Furthermore, $1 / n$ is a measure of surface heterogeneity or adsorption intensity, in which the surface becomes more heterogeneous as $1 / n$ approaches zero. The $1 / n$ value of 0.18 (close to zero) implies that the surface of TSAC is heterogeneous.

From Figure 1 and Table 2, Langmuir isotherm exhibits the best fit, suggesting a monolayer adsorption of MG onto TSAC. The separation factor $\left(R_{L}\right)$, a dimensionless constant of Langmuir isotherm was used to determine the favourability or practicability of the adsorption process. The mathematical expression of $R_{L}$ is given as follows:

$$
R_{L}=\frac{1}{1+b C_{o}}
$$

$R_{L}$ describes the selective nature of adsorption whether the adsorption is unfavourable when $R_{L}>1$, linear when $R_{L}=1$, favourable when $0<R_{L}<1$ or irreversible at $R_{L}=0$. The $R_{L}$ values ranging between 0.01 and 0.096 at the concentrations studied are in the range of 0 to 1 , indicating that the MG adsorption onto TSAC is favourable. Redlich-Peterson (R-P) model is a hybrid three-parameter empirical equation incorporating both Langmuir and Freundlich models [7]. The R-P isotherm yielded a good fit to the adsorption data. The value of R-P constant $g$ is 1, revealing an ideal Langmuir adsorption, thus further confirms the good applicability of Langmuir isotherm. The value of $g$ is usually near to 1 in the adsorption of large molecules due to the solid obstruction prevailing between the adsorbate and the pores of adsorbent. It can be concluded that the Langmuir and R-P models are suitable to describe the equilibrium adsorption of MG onto TSAC.

Table 2

Parameters of isotherm models

\begin{tabular}{|c|c|c|c|c|c|}
\hline \multicolumn{2}{|c|}{ Langmuir } & \multicolumn{2}{c|}{ Freundlich } & \multicolumn{2}{c|}{ Redlich-Peterson } \\
\hline$q_{m}$ & 156.1 & $n$ & 66.01 & $k_{R}$ & 43.4 \\
\hline$b$ & 0.28 & $k_{F}$ & 5.9 & $a_{R}$ & 0.28 \\
\hline$R^{2}$ & 0.775 & $R^{2}$ & 0.564 & $g$ & 1.00 \\
\hline$R M S E$ & 25 & $R M S E$ & 34.5 & $R^{2}$ & 0.775 \\
\hline & & & & $R M S E$ & 25 \\
\hline
\end{tabular}

\section{Comparison with other SBAs}

As can be seen from Table 3, sewage sludge from various origins possess high composition of carbon of up to $68.7 \%$, thus making them a suitable precursor for activated carbon (AC). The high carbon content of the precursor can improve the textural properties, surface area and yield of AC. Although most of sewage sludge are high in carbon content and rich in surface functional groups, the high ash content (>16\%) may impede the pore development during activation [2, 3, 8]. The presence of inorganic materials renders 
difficult ignition, consequently retards carbonization or pyrolysis. Inorganic matters may also clog the pores, so decreasing the surface area of adsorbent.

$\mathrm{KOH}$ and $\mathrm{ZnCl}_{2}$ are mainly used in the chemical activation of SBAs owing to the process that offers higher yield, lower pyrolysis temperature, shorter activation time and microporous AC. Generally, SBAs have surface area ranging from $\sim 5$ to $1832 \mathrm{~m}^{2} / \mathrm{g}$ as shown in Table 3.

Table 3

Preparation of sludge-based adsorbents (SBA) and their adsorption performances

\begin{tabular}{|c|c|c|c|c|c|c|c|c|c|c|c|c|}
\hline \multirow{2}{*}{$\begin{array}{l}\text { Type of } \\
\text { sludge }\end{array}$} & \multicolumn{2}{|c|}{$\mathrm{CC}[\%]$} & \multirow[b]{2}{*}{$\mathbf{A A}$} & \multirow[b]{2}{*}{ IR } & \multirow{2}{*}{$\begin{array}{l}\text { Activation } \\
\text { procedure }\end{array}$} & \multirow{2}{*}{$\begin{array}{c}\text { Yield } \\
{[\%]}\end{array}$} & \multirow{2}{*}{$\begin{array}{c}S_{B E T} \\
{\left[\mathrm{~m}^{2} / \mathrm{g}\right]}\end{array}$} & \multirow{2}{*}{$\begin{array}{l}\text { Mic. } \\
\text { [\%] }\end{array}$} & \multirow{2}{*}{$\begin{array}{c}v_{T} \\
{\left[\mathrm{~cm}^{3} /\right.} \\
\mathrm{g}]\end{array}$} & \multirow[b]{2}{*}{ Pollutant } & \multirow{2}{*}{$\begin{array}{c}Q_{e} \\
{[\mathrm{mg} / \mathrm{g}]}\end{array}$} & \multirow[b]{2}{*}{ Ref. } \\
\hline & RM & $\mathbf{A C}$ & & & & & & & & & & \\
\hline \multirow{3}{*}{$\begin{array}{l}\text { Sewage } \\
\text { sludge }\end{array}$} & \multirow{3}{*}{69} & 98 & $\mathrm{KOH}$ & \multirow{3}{*}{$1: 1$} & \multirow{3}{*}{$\begin{array}{l}\text { Pyrolysis } \mathrm{N}_{2} \text {, } \\
400^{\circ} \mathrm{C}, 2 \mathrm{~h} ; \\
\text { Activation } \mathrm{N}_{2} \text {, } \\
800^{\circ} \mathrm{C}, 0.5 \mathrm{~h}\end{array}$} & - & 920 & 61 & 0.59 & \multirow{3}{*}{$\begin{array}{l}\text { Contami- } \\
\text { nants from } \\
\text { PTCG }\end{array}$} & 8880 & \multirow{3}{*}{ [2] } \\
\hline & & 98 & $\mathrm{~K}_{2} \mathrm{CO}_{3}$ & & & - & 800 & 58 & 0.7 & & - & \\
\hline & & 95 & $\mathrm{H}_{3} \mathrm{PO}_{4}$ & & & - & $\sim 5$ & 20 & 0.02 & & - & \\
\hline \multirow{3}{*}{$\begin{array}{l}\text { Textile } \\
\text { sludge }\end{array}$} & \multirow{3}{*}{42} & - & $\mathrm{KI}$ & $1: 1$ & \multirow{3}{*}{$\begin{array}{l}\text { Activation } \\
500^{\circ} \mathrm{C}, 1 \mathrm{~h}\end{array}$} & 43.7 & 123 & 31.2 & 0.17 & \multirow{3}{*}{$\begin{array}{l}\text { Malachite } \\
\text { green }\end{array}$} & 36.9 & \multirow{3}{*}{ [3] } \\
\hline & & - & $\mathrm{KOH}$ & $1: 1$ & & 14.7 & 301 & 36.7 & 0.37 & & 108 & \\
\hline & & - & $\begin{array}{c}\mathrm{KI}, \\
\mathrm{KOH}\end{array}$ & $\begin{array}{c}0.7: \\
0.3: 1\end{array}$ & & 25 & 481 & 43 & 0.49 & & 167 & \\
\hline $\begin{array}{l}\text { Textile } \\
\text { sludge }\end{array}$ & 42 & - & $\begin{array}{c}\mathrm{KI}, \\
\mathrm{KOH}\end{array}$ & $\begin{array}{c}0.7: \\
0.3: 1\end{array}$ & $\begin{array}{c}\text { Activation } \\
700{ }^{\circ} \mathrm{C}, 1 \mathrm{~h}\end{array}$ & 18 & 1180 & 56.5 & 0.78 & \begin{tabular}{|c|}
$\begin{array}{c}\text { Methylene } \\
\text { blue }\end{array}$ \\
\end{tabular} & 382 & [6] \\
\hline $\begin{array}{l}\text { Textile } \\
\text { sewage } \\
\text { sludge }\end{array}$ & 23 & 7.5 & $\mathrm{KOH}$ & $0.5: 1$ & $\begin{array}{l}\text { Activation } \mathrm{N}_{2}, \\
700{ }^{\circ} \mathrm{C}, 45 \mathrm{~min}\end{array}$ & - & 336 & - & - & $\begin{array}{c}\text { Industrial } \\
\text { textile dyes } \\
\text { (RSB, } \\
\text { P2RFL) }\end{array}$ & \begin{tabular}{|c|}
8.54 \\
$(\mathrm{RSB})$ \\
5.4 \\
$(\mathrm{P} 2 \mathrm{RFL})$
\end{tabular} & [8] \\
\hline \multirow{3}{*}{$\begin{array}{l}\text { Sewage } \\
\text { sludge }\end{array}$} & \multirow{3}{*}{49} & - & $\mathrm{KOH}$ & $3: 1$ & $\begin{array}{l}\text { Activation } \mathrm{N}_{2} \text {, } \\
750^{\circ} \mathrm{C}, 0.5 \mathrm{~h}\end{array}$ & - & 1832 & 67.6 & 1.11 & \multirow{3}{*}{$\begin{array}{c}\text { 4-chloro- } \\
\text { phenol }\end{array}$} & 363 & \multirow{3}{*}{ [9] } \\
\hline & & - & $\mathrm{CO}_{2}$ & - & $\begin{array}{c}\text { Activation } \\
800^{\circ} \mathrm{C}, 2 \mathrm{~h}\end{array}$ & - & 94 & - & 0.04 & & 412 & \\
\hline & & - & Air & - & $\begin{array}{l}\text { Activation } \\
400^{\circ} \mathrm{C}, 2 \mathrm{~h}\end{array}$ & - & 92 & - & 0.06 & & 263 & \\
\hline $\begin{array}{l}\text { Sewage } \\
\text { sludge }\end{array}$ & 69 & - & $\mathrm{KOH}$ & $1: 1$ & $\begin{array}{c}\text { Carbonization } \\
\mathrm{N}_{2}, 400{ }^{\circ} \mathrm{C}, 2 \mathrm{~h} ; \\
\text { Activation } \mathrm{N}_{2} \text {, } \\
600{ }^{\circ} \mathrm{C}, 1 \mathrm{~h}\end{array}$ & - & 629 & - & 0.48 & $\begin{array}{l}\text { Dibenzo- } \\
\text { thiophene }\end{array}$ & 55.5 & [11] \\
\hline $\begin{array}{l}\text { WWTP } \\
\text { sludge }\end{array}$ & - & - & $\mathrm{ZnCl}_{2}$ & $5 \mathrm{M}$ & $\begin{array}{c}\text { Activation } \mathrm{N}_{2}, \\
500{ }^{\circ} \mathrm{C}, 2 \mathrm{~h}\end{array}$ & 35 & 721 & - & - & $\begin{array}{c}\text { Hydro- } \\
\text { phobic } \\
\text { organic } \\
\text { compounds }\end{array}$ & - & [12] \\
\hline $\begin{array}{c}\text { Biologic } \\
\text { al } \\
\text { sludge }\end{array}$ & 15 & - & $\mathrm{ZnCl}_{2}$ & $1: 1$ & $\begin{array}{c}\text { Activation } \mathrm{N}_{2} \\
800{ }^{\circ} \mathrm{C}, 1 \mathrm{~h}\end{array}$ & 20 & 632 & - & 0.51 & $\begin{array}{c}\text { Crystal } \\
\text { violet }\end{array}$ & 538 & [13] \\
\hline $\begin{array}{l}\text { Textile } \\
\text { sludge }\end{array}$ & 42 & - & $\begin{array}{c}\mathrm{KI}, \\
\mathrm{KOH}\end{array}$ & $\begin{array}{c}1.5: \\
0.5: 1\end{array}$ & $\begin{array}{c}\text { Activation } \\
700{ }^{\circ} \mathrm{C}, 1 \mathrm{~h}\end{array}$ & 22.4 & 984 & 63.6 & 0.55 & $\begin{array}{l}\text { Malachite } \\
\text { green }\end{array}$ & 156 & \begin{tabular}{|l|} 
This \\
study
\end{tabular} \\
\hline
\end{tabular}

AA: activating agent, RM: raw material, AC: activated carbon, $\mathrm{CC}$ : carbon content, $S_{B E T}$ : BET surface area, Mic.: microporosity, $v_{T}$ : total pore volume, WWTP: wastewater treatment plant, PTCG: pre-treated crude glycerol, RSB: Synozol Blue reactive, P2RFL: Setapers Yellow-Brown, $Q_{e}$ : maximum adsorption capacity

A study conducted by Monsalvo et al. [9] showed that the physical activation using $\mathrm{CO}_{2}$ and air produce AC with surface area lesser than $100 \mathrm{~m}^{2} / \mathrm{g}$. The high amount of inorganic matter in sludge severely inhibits the formation of pores during physical activation such as partial gasification of $\mathrm{CO}_{2}$ and air. On the other hand, $\mathrm{KOH}$ activation at $750{ }^{\circ} \mathrm{C}, 0.5 \mathrm{~h}$ gives an extremely high surface area of $1832 \mathrm{~m}^{2} / \mathrm{g}$ and microporosity of 
$68 \%$, but at the expense of high impregnation ratio of $3: 1$. A higher mass ratio of activating agent signifies a greater production cost and a lower yield, which are unfavourable in industrial applications. The adsorption capacities for 4-chlorophenol were found to be quite close despite the considerably different surface area, indicating that the surface chemistry may have a substantial effect in the adsorption of phenolic compounds. The presence of basic oxygen-containing groups and surface oxygen, nitrogen and sulphur complexes are beneficial for the removal of phenols [9].

Chemical activation is a single stage process, whereby both carbonization and activation occur simultaneously [10]. Nevertheless, a carbonization step can be done before chemical activation to produce char with rudimentary textural properties, which is more prone to chemical reaction [5]. As a result, the development of micropores and mesopores are maximized, leading to porous SBAs with high surface area. Overall, the two-step or char-impregnated chemical activation produces SBAs with higher surface area compared to direct chemical activation (Table 3). Hunsom and Autthanit [2] also reported the SBA with high surface area and microporosity of $920 \mathrm{~m}^{2} / \mathrm{g}$ and $61 \%$, respectively through a two-step process, i.e., carbonization at $400{ }^{\circ} \mathrm{C}$ for $2 \mathrm{~h}$ and activation at $800{ }^{\circ} \mathrm{C}$ for $0.5 \mathrm{~h}$. The same method was performed using $\mathrm{K}_{2} \mathrm{CO}_{3}$ and concentrated $\mathrm{H}_{3} \mathrm{PO}_{4}$. $\mathrm{KOH}$ and $\mathrm{K}_{2} \mathrm{CO}_{3}$ activation produce porous $\mathrm{ACs}$ than $\mathrm{H}_{3} \mathrm{PO}_{4}$ activation because at temperatures above $450{ }^{\circ} \mathrm{C}$, the phosphate and polyphosphate linkages continue to split and cause a decrease in crosslink density. As a result, the polyaromatic clusters grow and align, forming a closely compacted structure with a lower surface area [2].

Direct chemical activation using $\mathrm{KOH}$ generates SBA with a greater surface area compared to $\mathrm{ZnCl}_{2}$ activation, but the yield is only about $15 \%$ and it is often overlooked in most studies. It was discovered that by mixing $\mathrm{KI}$ and $\mathrm{KOH}$ at certain mass ratio during chemical activation, the yield and textural properties of the TSAC could be enhanced (Table 3). In this study, the composite, $\mathrm{KI}+\mathrm{KOH}$ activation was performed at $700{ }^{\circ} \mathrm{C}$ with impregnation ratio of $1.5: 0.5: 1$ (KI : KOH : TS), from which the resultant TSAC with a $984 \mathrm{~m}^{2} / \mathrm{g}$ surface area and $64 \%$ microporosity was obtained. This showed that the $\mathrm{KI}+\mathrm{KOH}$ activating agent possesses the pore drilling ability in ashy precursors without sacrificing the yield, and surface area and microporosity of TSAC. Despite being carried out in acidic conditions $(\mathrm{pH} \approx 2.1)$, the adsorption capacity of TSAC $\left(984 \mathrm{~m}^{2} / \mathrm{g}\right)$ was comparable to the sludge AC $\left(481 \mathrm{~m}^{2} / \mathrm{g}\right)$, indicating good versatility in lower $\mathrm{pH}$. Therefore, the future studies could be focused on $\mathrm{KI}+\mathrm{KOH}$ activation of ashy materials, stability and regeneration of SBAs and application to the real wastewater.

\section{Conclusion}

The conversion of sludge into adsorbent can overcome the expensive sludge disposal problem and alleviate the environmental pollution as a result of landfilling and sludge incineration. The $\mathrm{KI}+\mathrm{KOH}$ activating agent improves the yield and textural properties of TSAC, thus increasing the MG adsorption capacity. This work showed that the preparation of TSAC via $\mathrm{KI}+\mathrm{KOH}$ activation is feasible. Hence, it is proposed that certain areas such as $\mathrm{KI}+\mathrm{KOH}$ activation of various precursor, stability and regeneration of sludge-based activated carbon and its application to the real wastewater can be explored for future studies. 


\section{Acknowledgments}

The authors acknowledge the financial support from the Ministry of Education Malaysia through Fundamental Research Grant Scheme No. 4F995. Tang Shu Hui would like to express her appreciation for the UTM Zamalah scholarship.

\section{References}

[1] Idris A, Hashim R, Abdul Rahman R, Ahmad WA, Ibrahim Z, Abdul Razak PR, et al. Int J Eng Technol. 2007;4(2):228-34.

[2] Hunsom M, Autthanit C. Chem Eng J. 2013;229:334-43. DOI: 10.1016/j.cej.2013.05.120.

[3] Tang SH, Zaini MAA. Asia-Pac J Chem Eng. 2017;12(1):159-72. DOI: 10.1002/apj.2063.

[4] Patel H, Pandey S. J Hazard Mater. 2012;207:56-64. DOI: 10.1016/j.jhazmat.2011.05.028.

[5] Marsh H, Rodríguez-Reinoso F. Activated Carbon. Oxford: Elsevier; 2006. ISBN: 9780080444635.

[6] Tang SH, Zaini MAA. Desal Water Treat. 2019;138:335-45. DOI: 10.5004/dwt.2019.23332.

[7] Foo KY, Hameed BH. Chem Eng J. 2010;156(1):2-10. DOI: 10.1016/j.cej.2009.09.013.

[8] Kacan E. J Environ Manage. 2016;166:116-23. DOI: 10.1016/j.jenvman.2015.09.044.

[9] Monsalvo VM, Mohedano AF, Rodriguez JJ. Desalination. 2011;277(1):377-82. DOI: 10.1016/j.desal.2011.04.059.

[10] Tran HN, Chao HP, You SJ. Adsorpt Sci Technol. 2018;36(1-2):95-113. DOI: 10.1177/0263617416684837.

[11] Nunthaprechachan T, Pengpanich S, Hunsom M. Chem Eng J. 2013;228:263-71. DOI: 10.1016/j.cej.2013.04.067.

[12] Björklund K, Li LY. J Environ Manage. 2017;197:490-7. DOI: 10.1016/j.jenvman.2017.04.011.

[13] Streit AF, Côrtes LN, Druzian SP, Godinho M, Collazzo GC, Perondi D, et al. Sci Total Environ. 2019;660:277-87. DOI: 10.1016/j.scitotenv.2019.01.027. 